\title{
Enophthalmos as a rare manifestation of metastatic orbital involvement
}

\author{
Jacques de Keyser ${ }^{1}$, Marc Bruyland ${ }^{1}$, Jacques de Greve², Jan Bernheim ${ }^{3}$ and Guy \\ Ebinger ${ }^{1}$
}

Departments of ${ }^{\prime}$ Neurology and ${ }^{2}$ Internal Medicine, Akademisch Ziekenhuis Vrije Universiteit Brussel; and

${ }^{3}$ Department of Medicine, Jules Bordet Institute, Brussels, Belgium

\begin{abstract}
Summary: Two cases in which orbital metastasis produced enophthalmos, instead of the usual exophthalmos, are reported. Only fourteen other cases have been described previously and they are reviewed. At time of diagnosis of the enophthalmos, meningeal carcinomatosis coexisted in the first case and probably also in the second case. This association can lead to diagnostic errors with either the orbital metastasis or the meningeal carcinomatosis being missed. In addition, as in our second case, the enophthalmos can be the initial manifestation of cancer.
\end{abstract}

\section{Introduction}

In his 'System of Ophthalmology', Sir Stewart DukeElder (1974) states that enophthalmos is of much less clinical importance than exophthalmos, partly because its consequences are not so disastrous. However, he did not mention orbital metastasis in his list of causes that produce enophthalmos, a condition usually associated with a fatal outcome. Indeed, the topography of the orbit is such that a metastasis in this compartment normally produces proptosis. But in rare instances, the metastasis infiltrates extraocular muscles and orbital fat, causing retraction of the eyeball. Other tumours of the orbit do not present with this picture, unless they are associated with destruction of orbital bone.

\section{Case reports}

Case 1

A 55 year old woman presented with sharp pain and numbness in the lower part of the right face, which was quickly followed by diplopia and a left palpebral ptosis. Two years earlier, she had undergone a right mastectomy for an infiltrating mammary carcinoma

Jacques de Keyser, M.D.; Marc Bruyland, M.D.; Jacques de Greve, M.D.; Jan Bernheim, M.D.; Guy Ebinger, M.D.

Correspondence: J. de Keyser, Department of Neurology, Akademisch Ziekenhuis V.U.B., Laarbeeklaan 101, B-1090 Brussels, Belgium.

Accepted: 15 December 1983. and postoperatively she had received local radiation therapy and adjuvant combination chemotherapy. Examination showed sensory loss for all modalities in the territory of the right trigeminal nerve with absent corneal reflex, a left sided ptosis, enophthalmos and convergent squint in the primary position due to paralysis of the left lateral rectus muscle (Figure 1). The pupils were equal and reactive. A firm nodular mass was felt in the remaining breast, and was shown by mammography to have malignant features. Blood values, including carcinoembryonic antigen (CEA), were normal. Exophthalmometry confirmed a left sided enophthalmos of $3 \mathrm{~mm}$. Vision, fundi and visual fields were normal. Pharmacological testing for denervation of the pupil was negative. Cerebrospinal fluid examination (CSF) revealed the presence of malignant cells. The diagnosis of meningeal carcinomatosis was established but provided no clear explanation for the enophthalmos. Therefore, a computed tomographic (CT) scanning of the orbits was performed which showed a retrobulbar mass filling the medial side of the left orbit, without bone destruction (Figure 2). Local radiation therapy on the orbit and skull base, intrathecal methotrexate and systemic chemotherapy was started. This provided regression of the diplopia and facial pain and the enophthalmos stabilized. The patient died 20 months later.

Case 2

A 34 year old woman presented with a one-month history of intermittent diplopia and progressive ptosis

(C) The Fellowship of Postgraduate Medicine, 1985 


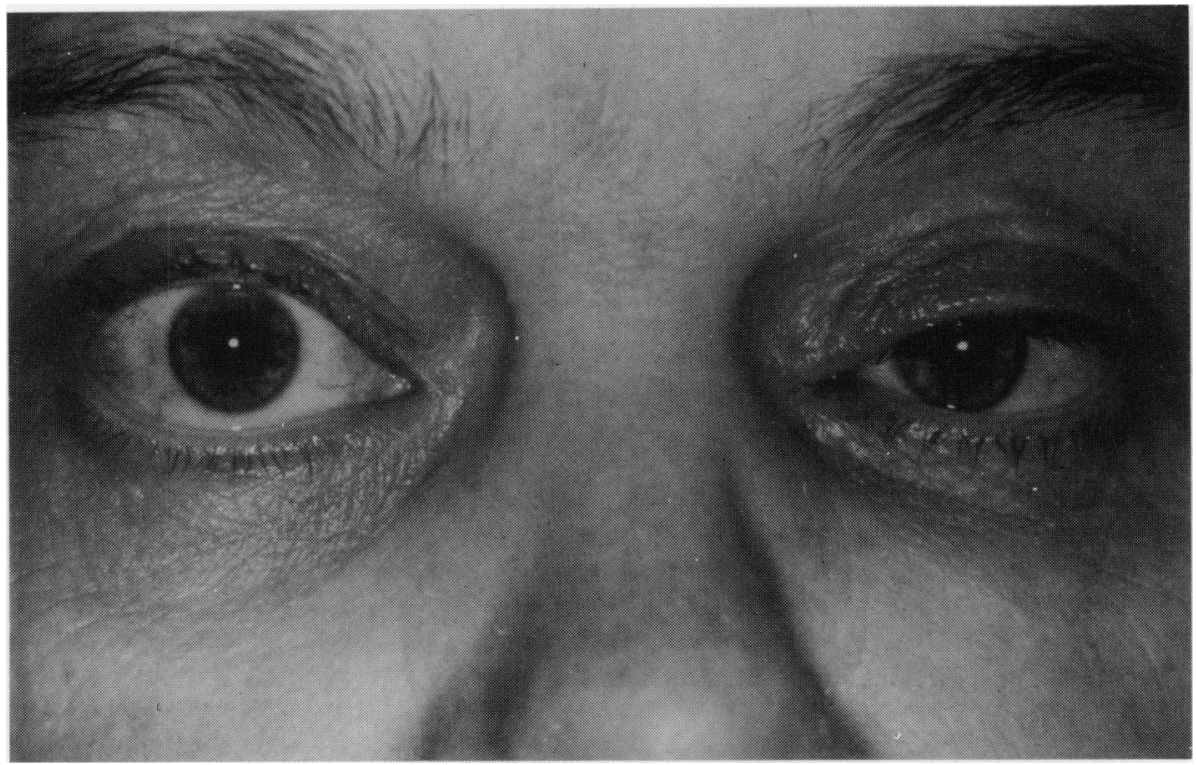

Figure 1 Case 1, showing left sided ptosis and enophthalmos.

of the right eye. She also complained of shooting pains in the left maxillary region. Examination disclosed a right sided ptosis, restricted ocular motility in all directions and enophthalmos. The rest of the neurological examination was normal. Vision and fundi were normal. Visual field testing revealed a superior temporal field defect of the right eye. Exophthalmometry with the Hertel exophthalmometer confirmed a right sided enophthalmos of $3 \mathrm{~mm}$. Radiographs of the skull and orbits were normal. A CT scan of the orbits showed densification of the right retrobulbar space. Subsequent general examination disclosed a mass of $1 \mathrm{~cm}$ diameter in the right breast. A right mastectomy was performed and histological examination showed an infiltrating duct carcinoma with a marked fibrous stroma. Blood chemistry showed moderate hypercalcaemia. Because of the facial pain, meningeal carcinomatosis was suspected, but CSF examination was normal. Subsequently, she underwent bilateral oophorectomy and received radiation therapy on the right orbit and systemic combination chemotherapy. The ocular signs stabilized but the facial pains persisted. Twenty months later, she was readmitted with headache, vomiting and seizures. CT scanning of the brain showed hydrocephalus. A ventriculoperitoneal shunt was placed and meningeal carcinomatosis was now demonstrated. She died nine months later of progressive disease.

\section{Discussion}

Fourteen cases of enophthalmos due to metastatic orbital disease have been described previously (Table $\frac{\partial}{\circ}$ I); others have been mentioned without clinical detail (Ferry, 1973; Ferry \& Front, 1974; Henderson \& $\frac{\varrho}{\Phi}$ Farrow, 1980; Hoyt \& Beeston, 1966). All patients $\stackrel{\square}{\Rightarrow}$ were female usually affected by a mammary carcin-응 oma. In two patients the primary neoplasm was situated in the stomach (Henderson \& Farrow, 1980, Larmande \& Rossazza, 1979); in one a colon neoplasm was detected (Ossoinig, 1969), and in another there 3 . was generalized carcinomatosis from an unknown: primary (Ossoinig, 1969). The presenting symptoms are diplopia, drooping of the upper eyelid or narrow- $\delta$ ing of the palpebral fissure, and occasionally orbital pain (Barroche et al., 1979; Manor, 1974; Sacks \&음 O'Grady, 1971).

Examination shows enophthalmos, always accom- $-\frac{D}{2}$ panied with impaired eye motility. Vision is rarely affected (Bullock \& Yanes, 1980; Manor, 1974). Palpation of the orbital rim sometimes reveals a hard ${ }^{N}$ mass (Ossoinig, 1969; Radnot \& Varga, 1975; Sacks \& N O'Grady, 1971). The visual field at the affected side can be amputated as in the case of Manor (1974) ande our second patient. Fundus examination revealed disc ${ }_{\mathbb{\Phi}}^{\complement}$ swelling in one case (Hoyt \& Beeston, 1966). Absent $\stackrel{\mathcal{P}}{+}$ corneal sensitivity at the side of the metastasis has been 0 reported twice (Barroche et al., 1979; Radnot \& Varga, 


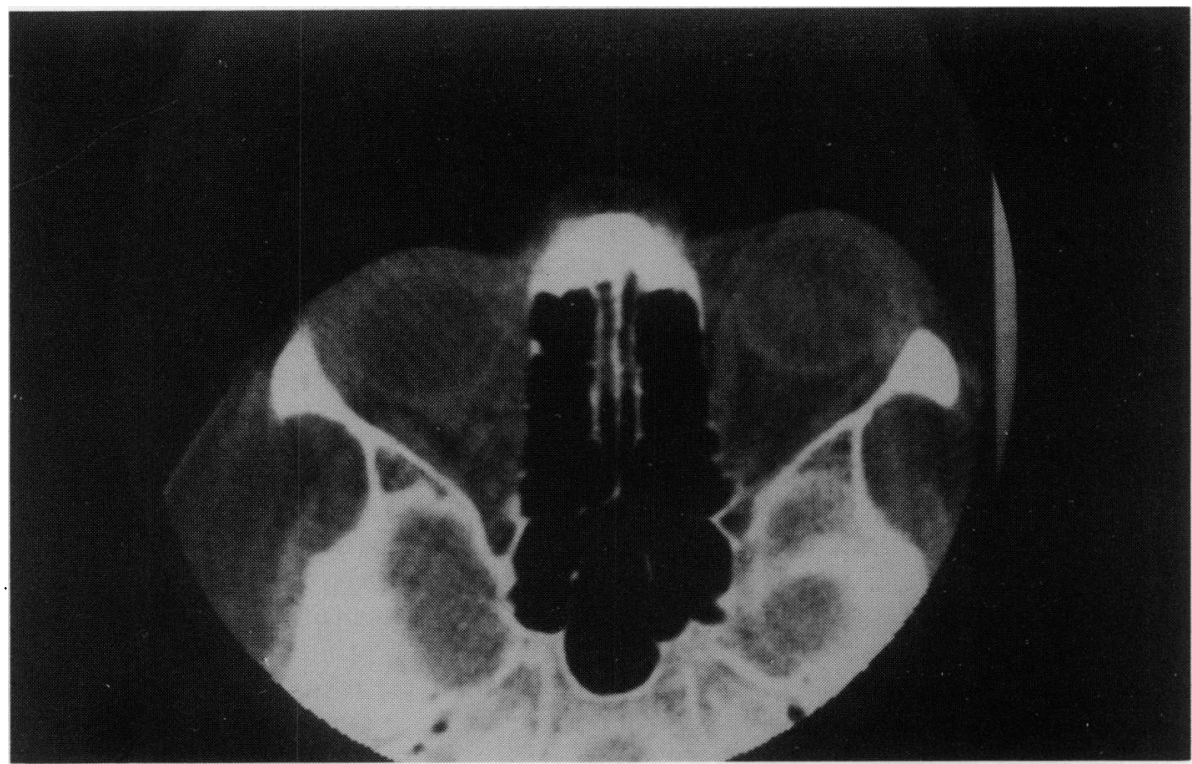

Figure 2 Computed tomography scan of orbits, Case 1, showing left retrobulbar mass and enophthalmos.

1975). Plain X-rays of the orbit are usually normal but in two cases erosion of the orbital bone was present (Manor, 1974; Ossoinig, 1969). Ultrasound and/or CT scanning of the orbits will establish the diagnosis.

The common histological feature of these neoplasms is the presence of a moderate to marked degree of fibrous tissue among the tumour cells. It is the infiltrative and fibroblastic character of this tumour type, also named scirrhous, that is responsible for the enophthalmos and restricted eye motility.

Our first case presented with meningeal carcinomatosis, in which ocular abnormalities are common (Katz et al., 1961). In this condition, an orbital metastasis producing enophthalmos can easily be

Table I Enopthalmos due to metastatic disease of the orbit - details of patients

\begin{tabular}{|c|c|c|c|}
\hline & Age (y) & $\begin{array}{l}\text { Interval after } \\
\text { discovery } \\
\text { primary tumour }\end{array}$ & Treatment (outcome) \\
\hline Lawson (1910) & $?$ & $18 \mathrm{~m}$ & no (progression S $18 \mathrm{~m}$ later) \\
\hline Biro (1941) & 41 & $1 \mathrm{y}$ & RT (progression S 4 m later) \\
\hline Ossoinig (1969) & 78 & $2 y$ & RT-CT (effect on S? - died $7 \mathrm{~m}$ later) \\
\hline , & 62 & $\star$ & no (died $9 \mathrm{~m}$ later) \\
\hline , & 56 & $\star$ & no (S unchanged 2 y later) \\
\hline $\begin{array}{l}\text { Sacks \& O'Grady } \\
\text { (1971) }\end{array}$ & 47 & $6 y$ & no (S relatively unchanged 1 y later) \\
\hline Manor (1974) & 72 & $6 \mathrm{~m}$ & CT (effect on S? - died $5 \mathrm{~m}$ later) \\
\hline Radnot \& Varga (1975) & 50 & $5 y$ & extirpation (?) \\
\hline Larmande \& Rossazza (1979) & 51 & $5 y$ & CT (stabilization $\mathrm{S}$ - died 1 y later) \\
\hline & 68 & $1 \mathrm{y}$ & no (died $6 \mathrm{~m}$ later) \\
\hline Barroche et al. (1979) & 55 & $2 y$ & RT-CT (improvement of ocular motility) \\
\hline Bullock \& Yanes (1980) & 69 & $5 y$ & $\begin{array}{l}\text { RT-HT (regression metastasis) + strabismus } \\
\text { surgery }\end{array}$ \\
\hline $\begin{array}{l}\text { Henderson \& Farrow } \\
\quad(1980)\end{array}$ & 45 & $4 y$ & $?(?)$ \\
\hline $\begin{array}{l}\text { pres. case } 1 \\
\text { pres. case } 2\end{array}$ & $\begin{array}{l}? \\
55 \\
34\end{array}$ & $\stackrel{\star}{2 y}$ & $\begin{array}{l}\text { ? (?) } \\
\text { RT-CT (disappearance of diplopia - died } 20 \mathrm{~m} \text { later) } \\
\text { RT-CT-HT (S stabilized - died } 29 \mathrm{~m} \text { later) }\end{array}$ \\
\hline
\end{tabular}

y:years; m:months; RT: radiotherapy; CT:chemotherapy; HT:hormonotherapy: S: eye symptomatology; ?: unknown; $\star$ : first manifestation of cancer. 
overlooked, and the eye manifestations attributed to Horner's syndrome and/or involvement of the oculomotor nerve. The additional finding of the orbital metastasis in our first patient allowed more rational treatment, including radiotherapy of the affected orbit with subsequent disappearance of the diplopia which was a serious symptom. However the reverse is also true with more serious implications, because it is the treatment of the meningeal carcinomatosis that determines further survival (HweeYong et al., 1982). The facial pains in our second patient were most probably a symptom of already existing meningeal carcinomatosis. We diagnosed the orbital metastasis but not the meningeal involvement. However, multiple CSF examinations are sometimes necessary to confirm this diagnosis (Bramlet et al., 1976; Olson et al., 1974). One other case (Biro, 1941) also had unexplained neurological signs that could be attributed to meningeal carcinomatosis, but CSF examination was not performed.

Because of the rarity of metastatic enophthalmos,

\section{References}

BARROCHE, G., GEHIN, P., SALMON, D., RENY, A. \& WEBER, M. (1979). Enophtalmie-Ophtalmoplegie par metastase orbitaire d'un carcinome mammaire. Revue d'Oto-neuro-ophtalmologie, 51, 447.

BIRO, I. (1941). Mit Enophthalmus einhergehende Mammakrebs-metastase in der Oribta. Acta Ophthalmologica, 19, 255.

BRAMLET, D., GILIBERTI, J. \& BENDER, J. (1976). Meningeal carcinomatosis. Neurology, 26, 287.

BULLOCK, J.D. \& YANES, B. (1980). Ophthalmic manifestations of metastatic breast cancer. Ophthalmology, 87, 961.

DUKE-ELDER, S. \& MAC FAUL, P.A. (1974). System of Ophthalmology Vol XIII, p. 1235. Henry Kimpton, London.

FERRY, A.P. (1973). The biological behavior and pathological features of carcinoma metastatic to the eye and orbit. Transactions of the American Ophthalmological Society, 71, 373.

FERRY, A.P. \& FRONT, R.L. (1974). Carcinoma metastatic to the eye and orbit. Archives of Opthalmology, 92, 276.

HENDERSON, J.W. \& FARROW, G.M. (1980). Orbital tumors, 2nd edn, pp. 456-457. Georg Tieme Verslag: Stuttgart, New York.

HOYT, W.F. \& BEESTON, D. (1966). The ocular fundus in neurologic disease. A diagnostic manual and stereo-atlas, p. 40. Mosby Company, Saint Louis.

HWEE-YONG, Y., BOH-SENG, Y., RASMUSSEN, S., LEVENS, the correct diagnosis has been missed over a long period in some cases. Patients have been labelled initially as suffering from hemifacial atrophy (Sacks $\& \mathcal{C}^{\circ}$ O'Grady, 1971), ocular myositis (Larmande \& Ros sazza, 1979) and myasthenia gravis (Bullock \& Yanes, 1980). In our second patient and in three otherso (Henderson \& Farrow, 1980; Ossoinig, 1969) thiso phenomenon was the first manifestation of cancer. We $\frac{\overline{\bar{\omega}}}{\bar{\alpha}}$ suggest that if a previously normal patient presents $\mathbb{D}_{\mathbb{D}}$ with enophthalmos, a CT scanning of the orbits and ap careful search for a breast or gastrointestinal tract neoplasm should ensue.

As far as treatment concerns, no serious conclusions $\overrightarrow{\vec{\omega}}$ can be drawn from previous reports (Table I). The combination of radiation therapy with chemotherapyo provoked disappearance of the diplopia in our first patient, and stabilized the eye symptomatology in our? second patient, who in addition also received hormon- otherapy. As for orbital metastasis in general, all $\vec{N}$ therapies are in essence only palliative, although they $\vec{A}$ may contribute to improve the quality of life.

M.E., HORTOBAGYI, G.N. \& BLUMENSCHEIN, G.R. (1982). Treatment of meningeal carcinomatosis in breast cuncer. Cancer, 49, 219.

KATZ, J.L., VALSAMIS, M.P. \& JAMPEL, R.S. (1961). Ocu signs in diffuse carcinomatous meningitis. American Jom nal of Ophthalmology, 52, 681.

LARMANDE, A. \& ROSSAZZA, C. (1979). Métastases orbitaires enophtalmiantes. Ophthalmologica, 179, 25.

LAWSON, A. (1910). Secondary contracting scirrhus of orbit Transactions of the Ophthalmological Society of the United Kingdom, 30, 236.

MANOR, R.S. (1974). Enophthalmos caused by orbita解 metastatic breast carcinoma. Acta Ophthalmologica, 52, 881.

OLSON, M.E., CHERNIK, N.L. \& POSNER, J.B. (1974) Infiltration of the leptomeninges by systemic cancer을 Archives of Neurology, 30, 122.

OSSOINIG, K. (1969). Enophthalmus ein Symptom bei Orbitatumoren. Berichte; Deutsche Ophthalmologische. Gesellschaft, 70, 82.

RADNOT, M. \& VARGA, M. (1975). Metastatic tumor of the orbit. Annals of Ophthalmology, 7, 1465.

SACKS, J.G. \& O'GRADY, B. (1971). Painful ophthalmoplegia and enophthalmos due to metastatic carcinoma: simula=o tion of essential facial hemiatrophy. Transactions of the American Academy of Opthalmology and Otolarytngology,, 75, 351. 